\title{
Seasonal, diurnal and nocturnal variations of carbonyl compounds in the semi-urban environment of Orléans, France
}

\author{
Zhaohui Jiang ${ }^{1,2}$, Benoît Grosselin ${ }^{1}$, Véronique Daële ${ }^{1}$, Abdelwahid Mellouki ${ }^{1, *}$, Yujing $\mathrm{Mu}^{3, *}$ \\ 1. Institut de Combustion, Aerothermique, Reactivité Environnement (ICARE), CNRS/OSUC 1C Avenue de la Recherche Scientifique, 45071 \\ Orléans Cedex 02, France \\ 2. College of Chemical and Biological Engineering, Changsha University of Science and Technology, Changsha 410004, China \\ 3. Research Center for Eco-Environmental Sciences, Chinese Academy of Sciences, Beijing 100085, China
}

\section{A R T I C L E I N F O}

Article history:

Received 27 April 2015

Revised 19 September 2015

Accepted 25 November 2015

Available online 7 January 2016

\section{Keywords:}

Carbonyls

Measurements

Semi-urban

\begin{abstract}
A B S T R A C T
Atmospheric carbonyls were measured at a semi-urban site in Orléans, France, from October 2010 to July 2011. Formaldehyde, acetaldehyde and acetone were found to be the most abundant carbonyls, with average concentrations of $3.1,1.0,2.0 \mathrm{ppb}$, respectively in summer, 2.3, 0.7, $2.2 \mathrm{ppb}$, respectively in autumn, 2.2, 1.0, $2.1 \mathrm{ppb}$, respectively in spring, and $1.5,0.7,1.1 \mathrm{ppb}$, respectively in winter. Photo-oxidation of volatile organic compounds (VOCs) was found to make a remarkable contribution to atmospheric carbonyls in the semi-urban site based on the distinct seasonal and diurnal variations of the carbonyls, as well as the significantly positive correlations between the carbonyls and ozone. The significantly negative correlations between $\mathrm{NO}_{x}$ and $\mathrm{O}_{3}$ as well as the carbonyls and the positive correlations between wind speed and $\mathrm{O}_{3}$ as well as the carbonyls implied that the carbonyls and $\mathrm{O}_{3}$ at the semi-urban site were probably formed during air mass transport from neighboring cities.
\end{abstract}

(c) 2015 The Research Center for Eco-Environmental Sciences, Chinese Academy of Sciences.

Published by Elsevier B.V.

\section{Introduction}

Carbonyl compounds are ubiquitous components of the atmosphere and play an important role in atmospheric chemistry. It is well documented that atmospheric carbonyls derive from both biogenic (vegetation) and anthropogenic sources (incomplete combustion of biomass and fossil fuels), including direct emission and secondary formation via photochemical conversion of volatile organic compounds (VOCs) emitted from both sources (Bakeas et al. 2003; Christensen et al. 2000; Ho et al. 2002; Nguyen et al. 2001; Possanzini et al. 2002). Some carbonyls are associated with adverse health impacts and most of them are precursors for radical and photooxidant formation in the atmosphere (Seinfeld and Pandis 1997; Possanzini et al. 2002).
To evaluate their influence on human health as well as atmospheric chemistry, field measurements of atmospheric carbonyls have been carried out in different areas, including urban (Cheng et al. 2014; Lü et al. 2010; Weng et al. 2009; Pang and Mu 2006; Pang and Lee 2010; Xu et al. 2010; Zhang et al. 2012; Feng et al. 2005; Ho et al. 2002; Nguyen et al. 2001; Possanzini et al. 2002), rural (Xie et al. 2008; Villanueva-Fierro et al., 2004; Wiedinmyer et al. 2001; Solberg et al. 2001; Shepson et al. 1991; Cheng et al. 2014) and remote areas (Singh et al. 2004; Zhou and Mopper 1993; Wagner et al. 2001; De Serves 1994). In comparison with urban areas, however, investigations on atmospheric carbonyls in rural or semi-urban areas are still sparse. Rural or semi-urban areas usually have less anthropogenic activities, and the atmospheric pollutants in these areas are often affected by air

\footnotetext{
* Corresponding authors. E-mails: mellouki@cnrs-orleans.fr (Abdelwahid Mellouki), yjmu@rcees.ac.cn (Yujing Mu).
} 
parcel transport from neighboring cities and as well as by vegetation, and hence measurements of atmospheric carbonyls in rural or semi-urban areas could provide scientific evidence about their various sources.

However, until now, research on carbonyl compounds in France has only been focused on large urban areas like Paris (Kalabokas et al. 1988). Very limited research work has been done on seasonal variations of carbonyls in the semi-urban atmosphere of France. In this study, atmospheric carbonyl compounds have been measured in a semi-urban site in Orléans, France, from October 2010 to July 2011. The major objectives were to determine their concentration levels and seasonal and diurnal variation characters, as well as possible sources, at this specific semi-urban site.

\section{Experimental}

\subsection{Sampling sites}

The map given in Fig. 1 shows the Orléans city site where the measurements were performed. Orléans city $\left(47^{\circ} 59^{\prime} 12^{\prime \prime} \mathrm{N}\right.$, $01^{\circ} 44^{\prime} 54^{\prime \prime} \mathrm{E}$ ) is located in the central part of France. In this study, a semi-urban site was selected as the sampling site, and it is positioned within the CNRS-campus (Centre National de la Recherche Scientifique) about $9.6 \mathrm{~km}$ away from Orléans city center. The site is close to a forest belt and farm. Air sampling was performed on a rooftop of the ICARE (Institut de Combustion, Aérothermique, Réactivité et Environnement) laboratory (about $10 \mathrm{~m}$ above ground) from October 2010 to July 2011. The detailed meteorological conditions and sampling dates are listed in Table 1.

\subsection{Carbonyl sampling and analysis}

The procedure used was based on EPA (Environmental Protection Agency) method TO-11 A (US EPA, 1999). The sampling medium was a silica cartridge. 2,4-dinitrophenylhydrazine (DNPH) had been purified by recrystallization in HPLC (high performance liquid chromatography) grade acetonitrile (ACN) three times. Each cartridge was rinsed with $10 \mathrm{~mL}$ of ACN and coated slowly with a solution containing $300 \mathrm{mg}$ of dry DNPH crystals and 2 or 3 drops of phosphoric acid in $200 \mathrm{~mL}$ fresh ACN. The cartridges were then connected in series and dried with a gentle flow of pure nitrogen (99.9999\%) for $15 \mathrm{~min}$, and then wrapped in aluminum foil, sealed in Teflon bags, and stored in the refrigerator at $4^{\circ} \mathrm{C}$ until use. Three blank cartridges from each batch were analyzed, and carbonyl contamination was found to be below the EPA blank criteria (formaldehyde $<0.05 \mu \mathrm{g} /$ cartridge; acetaldehyde $<0.06 \mu \mathrm{g} /$ cartridge; acetone $<0.08 \mu \mathrm{g} /$ cartridge and other aldehydes or ketones $<0.05 \mu \mathrm{g} /$ cartridge). It is reported in the literature that the DNPH cartridges can be stored for at least 6 months when refrigerated below $4^{\circ} \mathrm{C}$ (Druzik et al. 1990). In our study, the storage time under the same conditions was less than 30 days before use.

An automatic and multi-channel sampler self-designed in the group was used for collecting air samples. The sampler contains 12 channels, and each channel is connected to a DNPH cartridge; two electromagnetic valves at each side of the cartridges are controlled by a computer program. Samples were collected at 2-hr intervals from 0:00 to 24:00 (Coordinated Universal Time, UTC), which meant 12 samples could be collected in a sunny sampling day. Ozone interference was eliminated by an upstream cartridge scrubber coated with potassium iodide (Supelco, Bellefonte, USA). DNPH cartridges trap aldehydes and ketones through reactions with DNPH to form stable hydrazine derivatives. The sampling flow rate (0.9-1.1 L/min) was measured with a digital flow meter (DryCal DC Lite, Bios Corp, USA)). After sampling, the cartridges were sealed with silicon caps immediately, transported back to the laboratory and stored in the refrigerator before analysis. Each sampling day included one laboratory blank and one field blank. The field blank was treated identically to the samples except
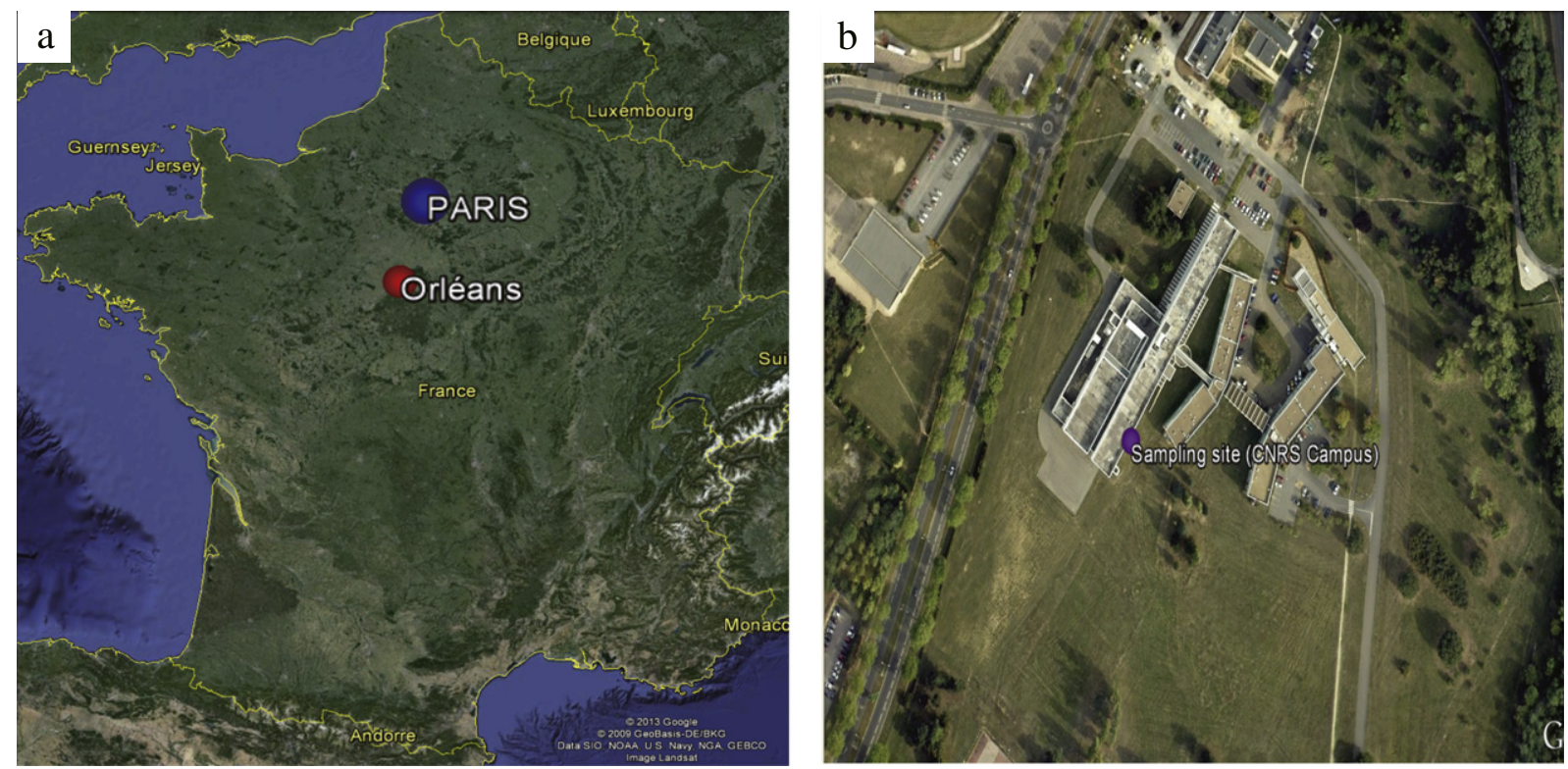

Fig. 1 - Sketch map of sampling sites in (a) Orléans in France and (b) CNRS (Centre National de la Recherche Scientifique)-campus. 
Table 1 - Meteorological parameters in the sampling periods at the semi-urban site in Orléans, France.

\begin{tabular}{clcccc} 
Sampling seasons & \multicolumn{1}{c}{ Sampling date } & Temperature $\left({ }^{\circ} \mathrm{C}\right)$ & Pressure $(\mathrm{hPa})$ & Wind speed $(\mathrm{km} / \mathrm{hr})$ & Weather condition \\
\hline Spring & 19-29 April, 2011 & $15.1 \pm 5.55$ & $1013.1 \pm 3.08$ & $9.62 \pm 3.14$ & Cloudy, sunny \\
Summer & 28 June-1 July, 2011 & $20.24 \pm 6.22$ & $1022 \pm 4.34$ & $13.74 \pm 4.88$ & Sunny \\
Autumn & 5-8 October, 2010 & $16.26 \pm 2.62$ & $1012.22 \pm 3.74$ & $11.81 \pm 3.5$ & Sunny \\
Winter & 17-21 January, 2011 & $3.73 \pm 3.7$ & $1030.77 \pm 3.83$ & $19.48 \pm 5.25$ & Cloudy, sunny \\
\hline
\end{tabular}

that no air was drawn through the cartridge. At each sampling site, two field samples were collected with a back-up cartridge to evaluate breakthrough.

The hydrazones formed by derivatization of carbonyls on DNPH were eluted slowly from the cartridges with $5.0 \mathrm{~mL}$ ACN, and the extracts were analyzed by HPLC. The analytical system consisted of a pump (2089PU, Jasco, Japan) and an injector, connected to a diode array detector (2010MD, Jasco, Japan) tuned to $360 \mathrm{~nm}$. Separation was performed on a Unisol C18 column ( $5 \mu \mathrm{m}, 4.6 \mathrm{~mm} \times 250 \mathrm{~mm}$, Agela, China) Isocratic mode was used for elution with acetonitrile/water $(77 / 23, \mathrm{~V} / \mathrm{V})$, and the flow rate of the mobile phase was $1 \mathrm{~mL} / \mathrm{min}$. Samples were injected by a Rheodyne valve equipped with a $20 \mu \mathrm{L}$ sampling loop.

\subsection{Quality assurance and quality control}

Identification and quantification of carbonyl compounds were based on their retention times and peak areas, respectively. The instrument was calibrated using seven standard concentrations $(0.01-1.0 \mu \mathrm{g} / \mathrm{mL})$ covering the field concentrations. Very good linearity was observed $\left(R^{2}>0.999\right)$ for HPLC calibration of the derivatives. A quality control (middle range calibration point) was introduced every day in order to detect eventual retention time shift and/or calibration fluctuation. Cartridge collection efficiency was determined using two cartridges in series, and over $98 \%$ of carbonyls were found in the first cartridge. Double extraction tests with ACN demonstrated that only one extraction ( $5 \mathrm{~mL}$ ) was necessary to perform a complete recovery of all carbonyls. Field blanks were generally of the same order of magnitude as the laboratory blanks, indicating that no contamination occurred. The relative standard deviations (RSD) of each set of calibration standard measurements $(n=10)$ did not exceed
$5 \%$ for all carbonyls identified. Method detection limits (MDLs) were determined by using ten replicate analyses of the working standards at the lowest concentration. The MDLs of the present study were estimated to be in the range of 0.2 to $0.4 \mu \mathrm{g} / \mathrm{m}^{3}$ for various carbonyls, for a $120 \mathrm{~L}$ sampling volume.

Ozone was measured using a commercial UV (ultraviolet) photometric analyzer (49C, Thermo Environmental Ins, USA). $\mathrm{NO}_{x}\left(\mathrm{NO}, \mathrm{NO}_{2}\right)$ were detected using a chemiluminescence NO$\mathrm{NO}_{2}-\mathrm{NO}_{x}$ analyzer (42i trace level, Thermo Electron Corporation, USA). Several meteorological parameters were monitored by an integrated sensor suite (Vantage Pro TM \& Vantage Pro 2 Plus TM Weather Stations, Davis Instruments Corp., USA), including wind speed and direction, temperature and relative humidity.

\subsection{Reagents}

All solvents employed were HPLC grade. Water was double distilled. The DNPH and ACN were purchased from Aldrich (Aldrich, Austria) and Carlo Erba (Carlo Erba, Italy). The standard mix used for HPLC calibration contained 13 carbonyl-DNPH derivatives (DNPH derivatives of formaldehyde, acetaldehyde, acrolein, acetone, propionaldehyde, crotonaldehyde, methacrolein, 2-butanone, butyraldehyde, benzaldehyde, valeraldehyde, $p$-tolualdehyde, hexaldehyde; from Supelco, Bellefonte, USA).

\section{Results and discussion}

\subsection{Average diurnal variation in each season}

Ten carbonyl compounds were identified in the ambient air, including formaldehyde, acetaldehyde, acetone, propionaldehyde,

Table 2 - Average concentration of the carbonyls in each season at the semi-urban site in Orléans, France (units: ppb).

\begin{tabular}{|c|c|c|c|c|}
\hline & Spring & Summer & Autumn & Winter \\
\hline & Mean \pm SD & Mean \pm SD & Mean \pm SD & Mean \pm SD \\
\hline Number of samples & 105 & 41 & 32 & 54 \\
\hline Formaldehyde & $2.16 \pm 0.59$ & $3.08 \pm 2.21$ & $2.28 \pm 0.82$ & $1.46 \pm 0.4$ \\
\hline Acetaldehyde & $1.02 \pm 0.28$ & $1.04 \pm 0.5$ & $0.66 \pm 0.29$ & $0.67 \pm 0.2$ \\
\hline Acetone & $2.08 \pm 0.72$ & $2 \pm 1.12$ & $2.23 \pm 1.08$ & $1.06 \pm 0.34$ \\
\hline Propionaldehyde & $0.29 \pm 0.15$ & $0.21 \pm 0.1$ & $0.13 \pm 0.08$ & $0.17 \pm 0.05$ \\
\hline Crotonaldehyde & nd & $0.84 \pm 0.45$ & $0.29 \pm 0.25$ & nd \\
\hline Methacrolein & nd & $0.10 \pm 0.15$ & $0.18 \pm 0.1$ & nd \\
\hline Benzaldehyde & $0.23 \pm 0.12$ & $0.17 \pm 0.23$ & $0.78 \pm 0.29$ & $0.4 \pm 0.14$ \\
\hline Valeraldehyde & $0.14 \pm 0.1$ & $0.1 \pm 0.05$ & $0.15 \pm 0.13$ & $0.12 \pm 0.1$ \\
\hline$p$-Tolualdehyde & $0.07 \pm 0.05$ & $0.18 \pm 0.24$ & $0.08 \pm 0.07$ & nd \\
\hline Hexaldehyde & $0.08 \pm 0.05$ & $0.09 \pm 0.04$ & $0.11 \pm 0.05$ & nd \\
\hline Total & $6.07 \pm 0.89$ & $7.81 \pm 1.02$ & $6.03 \pm 0.91$ & $3.88 \pm 0.53$ \\
\hline
\end{tabular}


crotonaldehyde, methacrolein, benzaldehyde, valeraldehyde, p-tolualdehyde and hexaldehyde. From Table 2, we see that formaldehyde, acetaldehyde and acetone were by far the principal carbonyls, being similar to those in Beijing (Pang and Mu 2006), in Guangzhou (Feng et al. 2005; Lü et al. 2010) and Hong Kong (Sin et al. 2001; Cheng et al. 2014), and were detected in every sample in each season. The percentage of the other carbonyls of the total carbonyls was about $20 \%$, and the most abundant high molecular weight carbonyl was benzaldehyde. The total concentrations of carbonyls decreased in order of summer > spring, autumn $>$ winter, and the concentrations of principal carbonyls (formaldehyde, acetaldehyde and acetone) in summer were higher than those in winter, which was similar to previous studies (Pang and Mu 2006; Lü et al. 2010; Cerón et al. 2007; Pal et al. 2008). However, most carbonyls except formaldehyde and butyraldehyde/isobutyraldehyde concentration ratios of summer to winter (S/W) were less than 1 at MK (Mong Kok) and UST (Hong Kong University of Science and Technology), Hong Kong (Cheng et al. 2014). The seasonal variation of carbonyls can be influenced by meteorological conditions like temperature, pressure, wind speed etc. (Pang and Mu 2006; Lü and Cai 2009; Lü et al. 2010; Cheng et al. 2014). At the semi-urban site, higher ambient temperature in summer (Table 1) could enhance the photochemical reactions and generate more carbonyls, while the similar meteorological conditions in spring and autumn might have contributed to the similar total concentrations in spring and autumn.

The average diurnal variations (11 days in spring, 4 days in summer, 4 days in autumn and 5 days in winter) of the three main carbonyls (formaldehyde, acetaldehyde and acetone) in each season are presented in Fig. 2. The very similar diurnal variations of acetaldehyde and acetone for summer, and formaldehyde for the seasons other than winter, with maximal values appearing in the noontime (around 14:00, UTC), indicated that photochemical formation was a dominant source for atmospheric carbonyls. In winter, the obvious elevation of carbonyl concentrations that appeared during the traffic rush hours of 17:00-19:00 implied that vehicular exhaust might be the primary source of carbonyls in winter. The results were in agreement with Pang and Mu (2006) and Zhang et al. (2012), who
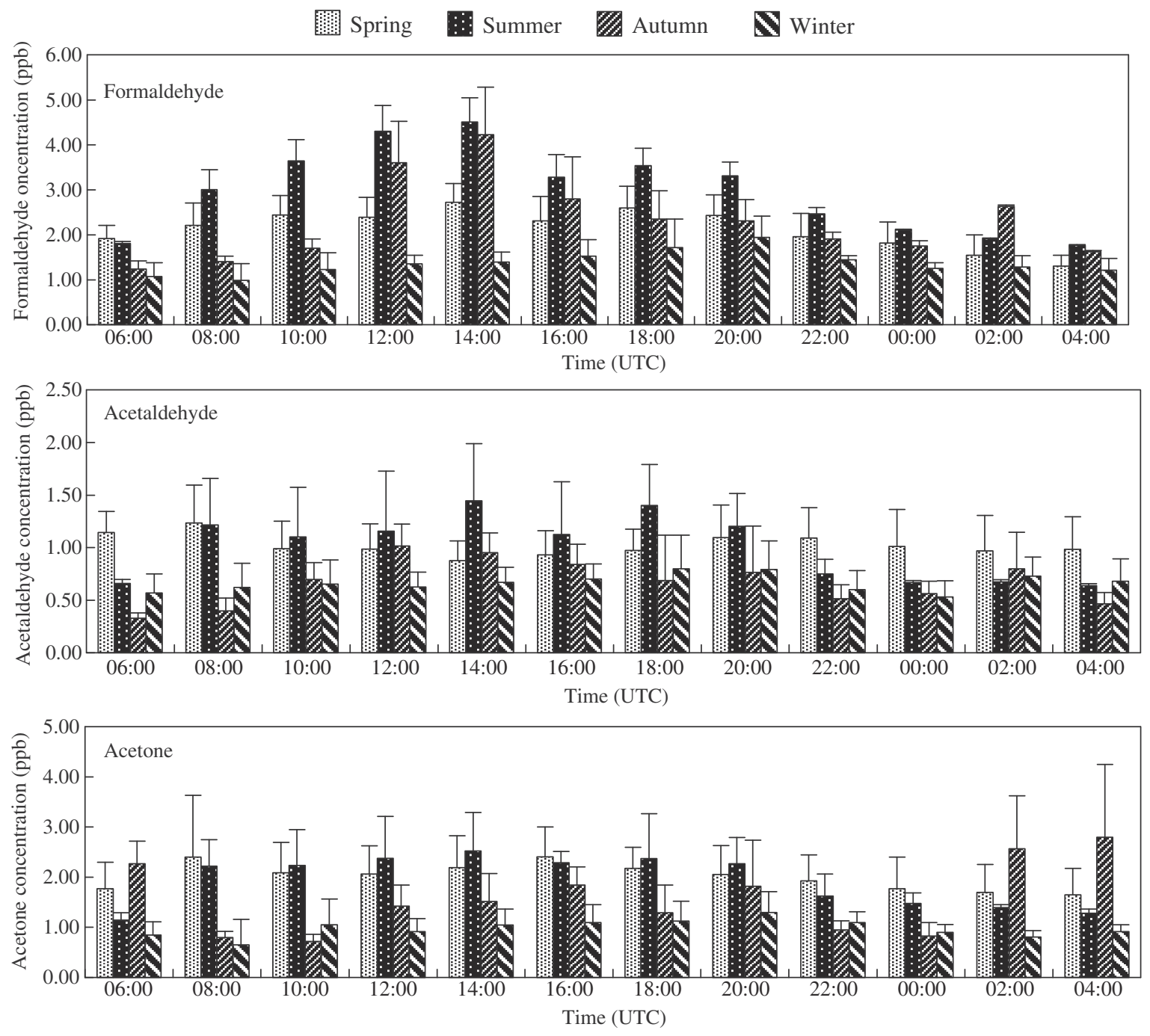

Fig. 2 - Average diurnal variations of the three main carbonyls in each season at the semi-urban site. UTC: Coordinated Universal Time. 
Table 3 - Correlation coefficients between carbonyls, $\mathrm{O}_{3}, \mathrm{NO}, \mathrm{NO}_{2}, \mathrm{NO}_{x}$ and meteorological factors in Orléans semi-urban ambient air in summer, 2011( $N=41)$.

Formaldehyde Acetaldehyde Acetone $\quad \mathrm{O}_{3} \quad \mathrm{NO} \quad \mathrm{NO}_{2} \quad \mathrm{NO}_{x} \quad \begin{gathered}\text { Relative } \\ \text { humidity }\end{gathered}$ Temperature Wind

\begin{tabular}{|c|c|c|c|c|c|c|c|c|c|c|}
\hline Formaldehyde & 1 & & & & & & & & & \\
\hline Acetaldehyde & $0.923^{* *}$ & 1 & & & & & & & & \\
\hline Acetone & $0.962^{* *}$ & $0.943^{* *}$ & 1 & & & & & & & \\
\hline $\mathrm{O}_{3}$ & $0.783^{* *}$ & $0.831^{* *}$ & $0.766^{* *}$ & 1 & & & & & & \\
\hline NO & -0.237 & 0.01 & -0.181 & $-0.451^{\text {*a }}$ & 1 & & & & & \\
\hline $\mathrm{NO}_{2}$ & $-0.474^{*}$ & -0.268 & -0.26 & $-0.705^{* *}$ & $0.738^{* *}$ & 1 & & & & \\
\hline $\mathrm{NO}_{x}$ & $-0.413^{*}$ & -0.183 & -0.244 & $-0.647^{* *}$ & $0.898^{* *}$ & $0.959^{* *}$ & 1 & & & \\
\hline Relative humidity & -0.233 & $-0.338^{*}$ & -0.205 & $-0.686^{* *}$ & 0.216 & $0.56^{*} 8$ & $0.455^{* *}$ & 1 & & \\
\hline Temperature & $0.787^{* *}$ & $0.824^{* *}$ & $0.78^{* *}$ & $0.91^{* *}$ & -0.048 & $-0.43^{* *}$ & $-0.301^{*}$ & $-0.699^{* *}$ & 1 & \\
\hline Wind & 0.263 & 0.267 & 0.242 & $0.411^{* *}$ & -0.039 & -0.235 & -0.17 & -0.144 & $0.407^{* *}$ & 1 \\
\hline
\end{tabular}

investigated the seasonal variation of atmospheric carbonyls in Beijing city. It should be noted that the time of increment of carbonyl concentrations began in the morning (8:00, UTC) in spring and summer, and much earlier than that in autumn. The relatively higher humidity in spring and summer than in autumn might favor HONO formation (the heterogeneous hydrolysis of $\mathrm{NO}_{2}$ on aerosol and particulate matter surfaces), which acts as an initiator for urban photochemistry (Atkinson 2000) and might be the reason for the elevation of carbonyl concentrations in the morning in summer and spring.

The diurnal variation trends of acetaldehyde and acetone in spring and autumn were different from those in summer and winter and also not distinct, suggesting that there were other sources of acetaldehyde and acetone. Acetone was sometimes found to be the most abundant carbonyl in the ambient air, especially in autumn, which is in accordance with previous studies (Feng et al. 2005; Pang and Mu 2006; Moussa et al. 2006; Lü et al. 2010). Acetone may be from solvent usage in construction or laboratories near the sampling site. Other than solvent usage near the sampling site, another explanation for the high acetone concentrations is that the lifetimes for acetone removal by photolysis and reaction with $\mathrm{OH}$ (40 and 20 days respectively) are longer than those of formaldehyde and acetaldehyde (1.5 hr and 1 day) in the atmosphere (Atkinson 2000).

\subsection{Correlations among carbonyls, $\mathrm{O}_{3}, \mathrm{NO}_{\mathrm{x}}$ and meteorological factors}

To further confirm that atmospheric photo-oxidation is the dominant source of ambient carbonyls in summer, the correlations among the carbonyls, $\mathrm{O}_{3}, \mathrm{NO}_{x}$ and meteorological factors in summer were analyzed (Table 3). Significant positive correlations among the three carbonyls, $\mathrm{O}_{3}$ and temperature further suggested that secondary formation of carbonyls at the semi-urban site was their dominant source. This conclusion could be confirmed by the typical daily variations of the carbonyls and ozone on one sunny day in summer (28-29 June 2011), as shown in Fig. 3. It is interesting to note that evidently positive correlations between $\mathrm{O}_{3}$ or carbonyls and wind speed as well as negative correlations between $\mathrm{O}_{3}$ or carbonyls and $\mathrm{NO}_{x}$ were observed. This conclusion could also be confirmed by the average diurnal variations of $\mathrm{NO}_{x}, \mathrm{O}_{3}$ and wind speed (Fig. 4) in Orléans semi-urban ambient air in summer, 2011. Wind speed usually acts as the key factor controlling atmospheric pollutant accumulation; the slower the wind speed is, the more

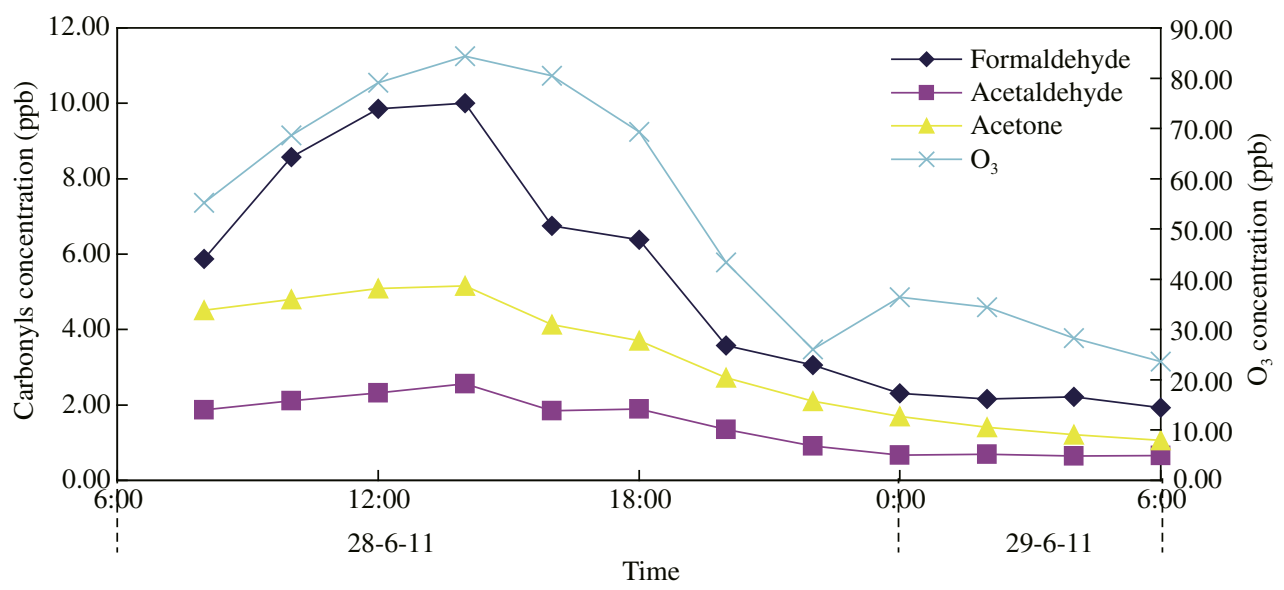

Fig. 3 - Daily variations of the carbonyls and ozone in Orléans semi-urban ambient air on a sunny day in summer (28-29 June 2011). 


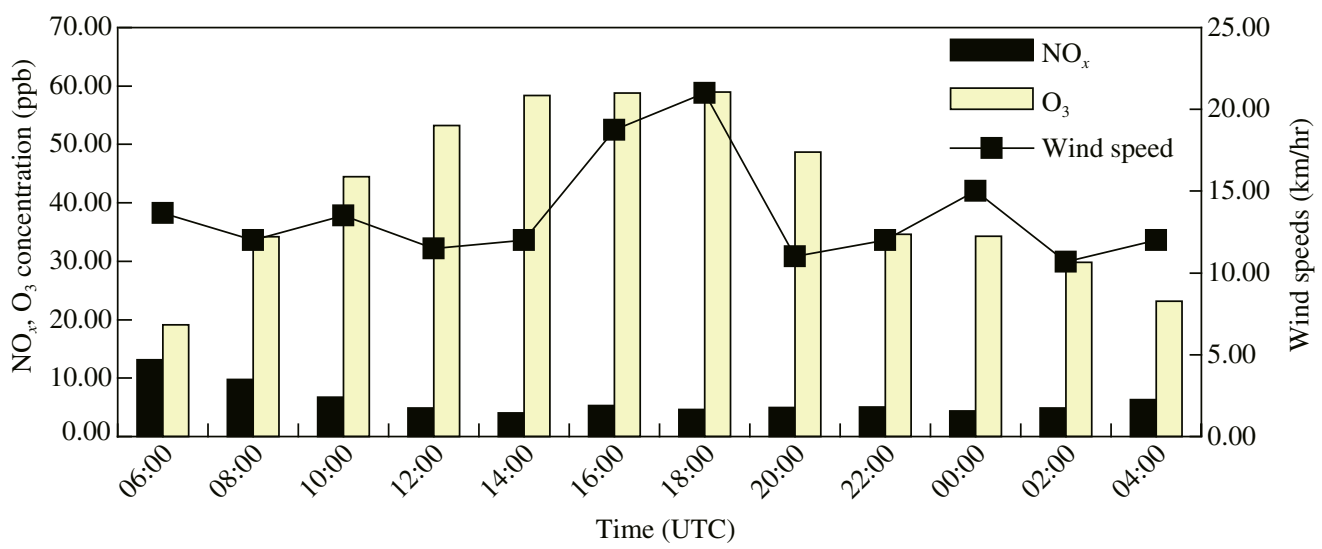

Fig. 4 - Average diurnal variations of $\mathrm{NO}_{x}, \mathrm{O}_{3}$ and wind speed in Orléans semi-urban ambient air in summer, 2011.

accumulation of pollutants occurs. The positive correlation between the wind speed and $\mathrm{O}_{3}$ or carbonyls at the semi-urban site indicated that $\mathrm{O}_{3}$ and carbonyls were mainly formed in air parcels transported from neighboring cities, such as Orléans. The significantly negative correlation between $\mathrm{O}_{3}$ and $\mathrm{NO}_{x}$ implied that evident titration of $\mathrm{O}_{3}$ by $\mathrm{NO}$ occurred at the semi-urban site. Because air parcels experiencing long term transport usually become aged, with a deficit of $\mathrm{NO}_{x}$, the evident titration of $\mathrm{O}_{3}$ by $\mathrm{NO}$ at the semi-urban site was ascribed to the high $\mathrm{NO}_{x}$ emissions from both local sources and the neighboring cities. The negative correlation between the three carbonyls and $\mathrm{NO}_{x}$ suggested that local automobile exhaust only made a minor contribution to atmospheric formaldehyde.

\subsection{Ratios of formaldehyde/acetaldehyde}

The ratio of formaldehyde/acetaldehyde (C1/C2) has been widely used as an indicator of a biogenic source for formaldehyde (Shepson et al. 1991). C1/C2 ratios were reported to vary from about 1 in urban areas (Ho et al. 2002; Feng et al. 2005; Pang and $\mathrm{Mu}$ 2006; Xu et al. 2010) to about 10 in deciduous forests (Jacob and Wofsy 1988; Shepson et al. 1991). This high value of C1/C2 ratio implies that the photo-oxidation of biogenic hydrocarbons such as isoprene yields more formaldehyde than acetaldehyde (Lloyd et al. 1983; Shepson et al. 1991; Duane et al. 2002). As listed in Table 4, the average C1/C2 ratio in this study was in good agreement with that reported by Villanueva-Fierro et al. (2004), who conducted measurement at rural areas near a forest in Mexico, but evidently greater than those measured at urban areas (Tanner et al. 1988; Grosjean et al. 1996; Possanzini et al. 2000; Xu et al. 2010; Lü et al. 2010), indicating that the photo-oxidation of biogenic hydrocarbons played an important role in atmospheric carbonyl formation at the sampling site. The extremely high value of C1/C2 at a suburban site in New Jersey was also ascribed to high isoprene emission from vegetation (Zhang et al. 1994).

The daily variation of C1/C2 (Fig. 5) also revealed the source of the carbonyls at the semi-urban ambient site. The $\mathrm{C} 1 / \mathrm{C} 2$ ratio of about 1 at midnight was in good agreement with those observed in urban areas, implying that anthropogenic emissions were the dominant sources. By contrast, photo-oxidation of biogenic isoprene became the dominant source during daytime, as the C1/C2 ratio evidently increased, with a maximal value of 3.46 around 14:00, when biogenic isoprene emission was the highest under the strongest sunlight irradiation and the high air temperature.

\subsection{Comparison with other cities}

Data obtained in this study represented the first measurements of carbonyls in the investigated semi-urban site in France. The levels of atmospheric carbonyls measured in different areas are listed in Table 5 for comparison. Atmospheric carbonyl levels measured during this study are close to the values in a forested zone of Langmuir, Mexico reported by Villanueva-Fierro et al. (2004), in a rural site of Ontario,

\section{Table 4 - Comparison of formaldehyde/acetaldehyde (C1/C2) concentration ratio in Orléans and in other areas.}

\begin{tabular}{|c|c|c|c|}
\hline Locations & $\mathrm{C} 1 / \mathrm{C} 2$ ratio (ppb/ppb) & Range & Reference \\
\hline Orléans, France (semi-urban) & 2.44 & $1.24-7.59$ & This work \\
\hline Vila Isabel, Brazil (urban) & 0.7 & & Tanner et al. (1988) \\
\hline New Jersey, USA (suburban) & 5.8 & $1.1-22$ & Zhang et al. (1994) \\
\hline Los Angeles, USA (urban) & 1.3 & $0.64-3.13$ & Grosjean et al. (1996) \\
\hline Montelibretti, Italy (urban) & 1.2 & & Possanzini et al. (2000) \\
\hline Beijing, China (urban) & 1.1 & & Xu et al. (2010) \\
\hline Langmuir, Mexico (forested) & 2.3 & & Villanueva-Fierro et al. (2004) \\
\hline Socorro, Mexico (rural) & 2.4 & & Villanueva-Fierro et al. (2004) \\
\hline UST, Hong Kong (background) & 2.16 & & Cheng et al. (2014) \\
\hline Guangzhou, China (urban) & 0.97 & $0.27-1.95$ & Lü et al. (2010) \\
\hline
\end{tabular}

UST: Hong Kong University of Science and Technology. 


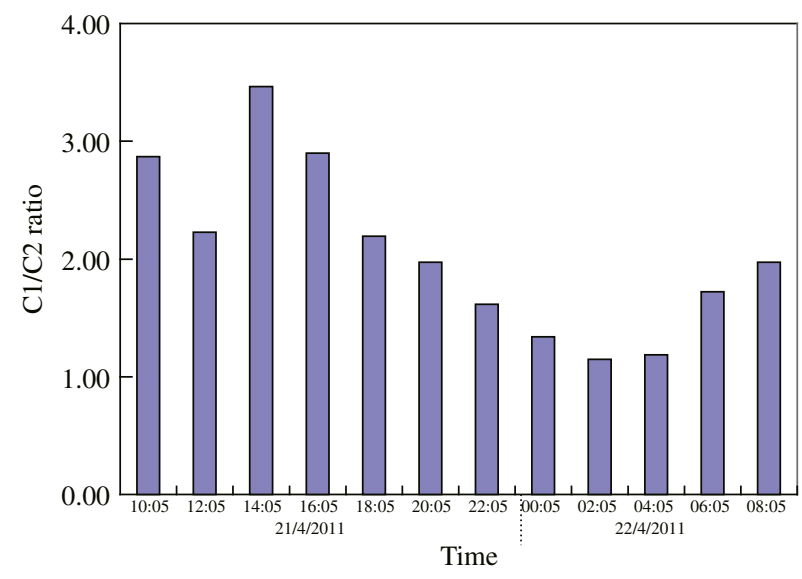

Fig. 5 - Daily concentration ratio variations of formaldehyde/ acetaldehyde (C1/C2) measured during 21-22 April 2011 at semi-urban site, Orléans.

Canada reported by Shepson et al. (1991) and in a background site of UST, Hong Kong reported by Cheng et al. (2014), but significantly lower than those reported in urban areas in the world (Pang and Mu 2006; Feng et al. 2005; Moussa et al. 2006; Kalabokas et al. 1988; Possanzini et al. 1996).

\section{Conclusions}

The ambient levels and possible sources of a series of carbonyls around the city of Orléans (Centre of France) were evaluated for the first time in this study. Formaldehyde, acetaldehyde and acetone were the principal carbonyls. The diurnal variation of the carbonyls in four seasons and the significantly positive correlations between carbonyls and ozone indicated that photo-oxidation of hydrocarbons was the major source for carbonyls. The evidently positive correlations between the carbonyls (and $\mathrm{O}_{3}$ ) and wind speed but negative correlation between $\mathrm{NO}_{x}$ and wind speed implied that the atmospheric carbonyls as well as $\mathrm{O}_{3}$ in the semi-urban site were strongly affected by transport of air parcels from urban areas, such as Orléans and Paris. Compared with urban areas, the relatively high ratio of formaldehyde to acetaldehyde in the semi-urban site indicated that biogenic emission of VOCs made an evident contribution to the carbonyls.

\section{Acknowledgments}

This work was supported by the Region Centre of France, the Chinese National Natural Science Foundation (No. 21307008), and Changsha Science and Technology Project (No. K1403048-31).

\section{R E F E R E N C E S}

Atkinson, R., 2000. Atmospheric chemistry of VOCs and $\mathrm{NO}_{x}$. Atmos. Environ. 34 (12-14), 2063-2101.

Báez, A.P., Padilla, H., Cervantes, J., Pereyra, D., Torres, M.C., Garcia, R., et al., 2001. Preliminary study of the determination of ambient carbonyls in Xalapa City, Veracruz, Mexico. Atmos. Environ. 35 (10), 1813-1819.

Bakeas, E.B., Argyris, D.I., Siskos, P.A., 2003. Carbonyl compounds in the urban environment of Athens, Greece. Chemosphere 52 (5), 805-813.

Cerón, R.M., Cerón, J.G., Muriel, M., 2007. Diurnal and seasonal trends in carbonyl levels in a semi-urban coastal site in the Gulf of Campeche, Mexico. Atmos. Environ. 41 (1), 63-71.

Cheng, Y., Lee, S.C., Huang, Y., Ho, K.F., Ho, S.S.H., Yau, P.S., et al., 2014. Diurnal and seasonal trends of carbonyl compounds in roadside, urban, and suburban environment of Hong Kong. Atmos. Environ. 89, 43-51.

Christensen, C.S., Skov, H., Nielsen, T., Lohse, C., 2000. Temporal variation of carbonyl compound concentrations at a semi-rural site in Denmark. Atmos. Environ. 34 (2), 287-296.

De Serves, C., 1994. Gas phase formaldehyde and peroxide measurements in the Arctic atmosphere. J. Geophys. Res. 99 (D12), 25391-25398.

US EPA (US Environmental Protection Agency), 1999. Method TO-11 A. Determination of Formaldehyde in Ambient Air Using Adsorbent Cartridge Followed by High Performance Liquid Chromatography (HPLC). Active Sampling Methodology.Research Triangle Park, NC, USA

Druzik, C.M., Grosjean, D., Van Neste, A., Parmar, S.S., 1990. Sampling of atmospheric carbonyls with small DNPH coated C18 cartridges and liquid chromatography analysis with diode array detection. Int. J. Anal. Chem. 38 (4), 495-512.

Duane, M., Poma, B., Rembges, D., Astorga, C., Larsen, B.R., 2002. Isoprene and its degradation products as strong ozone precursors in Insubria, Northern Italy. Atmos. Environ. 36 (24), 3867-3879.

Feng, Y.L., Wen, S., Chen, Y.J., Wang, X.M., Lü, H.X., Bi, X.H., et al., 2005. Ambient levels of carbonyl compounds and their sources in Guangzhou China. Atmos. Environ. 39 (10), 1789-1800

Table 5 - Comparison between carbonyl level in Orléans and those in other areas (units: ppb).

\begin{tabular}{lcccll}
\multicolumn{1}{c}{ Locations } & Formaldehyde & Acetaldehyde & Acetone & Atmosphere & Reference \\
\hline Orléans, France & 2.2 & 0.9 & 1.87 & Semi-urban & This work \\
Beijing, China & 12.1 & 5.66 & 6.99 & Urban & Pang and Mu (2006) \\
Guangzhou, China & 11.14 & 4.62 & 7.48 & Urban & Feng et al. (2005) \\
Beirut, Lebanon & 4.6 & 2.1 & 5.0 & Urban & Moussa et al. (2006) \\
Paris, France & 10.5 & 4.4 & & Urban & Kalabokas et al. (1988) \\
Langmuir, Mexico & 2.3 & 1.0 & 1.2 & Forested zone & Villanueva-Fierro et al. (2004) \\
Rome, Italy & 17.0 & 9.3 & 6.8 & Urban & Possanzini et al. (1996) \\
Ontario, Canada & 1.8 & 0.57 & 1.6 & Rural & Shepson et al. (1991) \\
Xalapa, Mexico & 3 & 11.6 & 3.5 & Urban & Báez et al. (2001) \\
Socorro, Mexico & 3.4 & 1.4 & 2.4 & Rural & Villanueva-Fierro et al. (2004) \\
Los Angeles, USA & 5.3 & 4.0 & 1.6 & Urban & Grosjean et al. (1996) \\
UST, Hong Kong & 1.95 & 0.62 & & Background & Cheng et al. (2014) \\
\hline
\end{tabular}


Grosjean, E., Grosjean, D., Fraser, M.P., Cass, G.R., 1996. Air quality model evaluation data for organics. 2. $\mathrm{C}_{1}-\mathrm{C}_{14}$ carbonyls in Los Angeles air. Environ. Sci. Tech. 30 (9), 2687-2703.

Ho, K.F., Lee, S.C., Louie, P.K.K., Zou, S.C., 2002. Seasonal variation of carbonyl compound concentrations in urban area of Hong Kong. Atmos. Environ. 36 (8), 1259-1265.

Jacob, D.J., Wofsy, S.C., 1988. Photochemistry of biogenic emissions over the Amazon forest. J. Geophys. Res. 93 (D2), 1477-1486.

Kalabokas, P., Carlier, P., Fresnet, P., Mouvier, G., Toupance, G., 1988. Field studies of aldehyde chemistry in the Paris area. Atmos. Environ. 22 (1), 147-155.

Lloyd, A.C., Atkinson, R., Lurmann, F.W., Nitta, B., 1983. Modeling potential ozone impacts from natural hydrocarbons-I. Development and testing of chemical mechanism for the $\mathrm{NO}_{\mathrm{x}}$-air photo oxidations of isoprene and $\alpha$-pinene under ambient conditions. Atmos. Environ. 17 (10), 1931-1950.

Lü, H.X., Cai, Q.Y., 2009. Progresses on the research of carbonyl compounds in atmosphere. Ecol. Environ. Sci. 18 (4), 1533-1539.

Lü, H.X., Cai, Q.Y., Wen, S., Chi, Y.G., Guo, S.J., Sheng, G.Y., et al., 2010. Seasonal and diurnal variations of carbonyl compounds in the urban atmosphere of Guangzhou, China. Sci. Total Environ. 408 (17), 3523-3529.

Moussa, S.G., El-Fadel, M., Saliba, N.A., 2006. Seasonal, diurnal and nocturnal behaviors of lower carbonyl compounds in the urban environment of Beirut, Lebanon. Atmos. Environ. 40 (14), 2459-2468.

Nguyen, H.T.H., Takenaka, N., Bandow, H., Maeda, Y., De Oliva, S.T., Botelho, M.M.F., et al., 2001. Atmospheric alcohols and aldehydes concentrations measured in Osaka, Japan and in Sao Paulo, Brazil. Atmos. Environ. 35 (18), 3075-3083.

Pal, R., Kim, K.H., Hong, Y.J., Jeon, E.C., 2008. The pollution status of atmospheric carbonyls in a highly industrialized area. J. Hazard. Mater. 153 (3), 1122-1135.

Pang, X.B., Lee, X.Q., 2010. Temporal variations of atmospheric carbonyls in urban ambient air and street canyons of a Mountainous city in Southwest China. Atmos. Environ. 44 (17), 2098-2106.

Pang, X.B., Mu, Y.J., 2006. Seasonal and diurnal variations of carbonyl compounds in Beijing ambient air. Atmos. Environ. 40 (33), 6313-6320.

Possanzini, M., Di Palo, V., Petricca, M., Fratarcangeli, R., Brocco, D., 1996. Measurements of lower carbonyls in Rome ambient air. Atmos. Environ. 30 (22), 3757-3764.

Possanzini, M., Di Palo, V., Brancaleoni, E., Frattoni, M., Ciccioli, P., 2000. A train of carbon and DNPH-coated cartridges for the determination of carbonyls from $C_{1}$ to $C_{12}$ in air and emission samples. Atmos. Environ. 34 (29-30), 5311-5318.

Possanzini, M., Di Palo, V., Cecinato, A., 2002. Sources and photodecomposition of formaldehyde and acetaldehyde in Rome ambient air. Atmos. Environ. 36 (19), 3195-3201.

Seinfeld, J.H., Pandis, S.N., 1997. Atmospheric Chemistry and Physics. Wiley, New York, pp. 234-336.

Shepson, P.B., Hastie, D.R., Schiff, H.I., Polizzi, M., Bottenheim, J.W., Anlauf, K., et al., 1991. Atmospheric concentrations and temporal variations of $C_{1}-C_{3}$ carbonyl compounds at two rural sites in central Ontario. Atmos. Environ., Part A 25 (9), 2001-2015.

Sin, D.W.M., Wong, Y.C., Louie, P.K.K., 2001. Trends of ambient carbonyl compounds in the urban environment of Hong Kong. Atmos. Environ. 35 (34), 5961-5969.

Singh, H.B., Salas, L.J., Chatfield, R.B., Czech, E., Fried, A., Walega, J., et al., 2004. Analysis of the atmospheric distribution, sources, and sinks of oxygenated volatile organic chemicals based on measurements over the Pacific during TRACE-P. J. Geophys. Res. 109 (D15). http://dx.doi.org/10.1029/ 2003JD003883.

Solberg, S., Dye, C., Walker, S.E., Simpson, D., 2001. Long-term measurements and model calculations of formaldehyde at rural European monitoring sites. Atmos. Environ. 35 (2), 195-207.

Tanner, R.L., Miguel, A.H., De Andrade, J.B., Gaffney, J.S., Streit, G.E., 1988. Atmospheric chemistry of aldehydes: enhanced peroxyacetyl nitrate formation from ethanol-fueled vehicular emissions. Environ. Sci. Technol. 22 (9), 1026-1034.

Villanueva-Fierro, I., Popp, C.J., Martin, R.S., 2004. Biogenic emissions and ambient concentrations of hydrocarbons carbonyl compounds and organic acids from ponderosa pine and cottonwood trees at rural and forested sites in Central New Mexico. Atmos. Environ. 38 (2), 249-260.

Wagner, V., Schiller, C., Fischer, H., 2001. Formaldehyde measurements in the marine boundary layer of the Indian Ocean during the 1999 INDOEX cruise of the R/V Ronald $\mathrm{H}$. Brown. J. Geophys. Res. 106 (D22), 28529-28538.

Weng, M.L., Zhu, L.Z., Yang, K., Chen, S.G., 2009. Levels and health risks of carbonyl compounds in selected public places in Hangzhou, China. J. Hazard. Mater. 164 (2-3), 700-706.

Wiedinmyer, C., Friedfeld, S., Baugh, W., Greenberg, J., Guenther, A., Fraser, M., et al., 2001. Measurement and analysis of atmospheric concentrations of isoprene and its reaction products in central Texas. Atmos. Environ. 35 (6), 1001-1013.

Xie, X., Shao, M., Liu, Y., Lu, S.H., Chang, C.C., Chen, Z.M., 2008. Estimate of initial isoprene contribution to ozone formation potential in Beijing China. Atmos. Environ. 42 (24), 6000-6010.

Xu, Z., Liu, J.F., Zhang, Y.J., Liang, P., Mu, Y.J., 2010. Ambient levels of atmospheric carbonyls in Beijing during the 2008 Olympic Games. J. Environ. Sci. 22 (9), 1348-1356.

Zhang, J.F., Lioy, P.J., He, Q.C., 1994. Characteristics of aldehydes: concentrations, sources, and exposures for indoor and outdoor residential microenvironments. Environ. Sci. Technol. 28 (1), 146-152.

Zhang, Y.J., Mu, Y.J., Liu, J.F., Mellouki, A., 2012. Levels, sources and health risks of carbonyls and BTEX in the ambient air of Beijing, China. J. Environ. Sci. 24 (1), 124-130.

Zhou, X.L., Mopper, K., 1993. Carbonyl compounds in the lower marine troposphere over the Caribbean Sea and Bahamas. J. Geophys. Res. 98 (C2), 2385-2392. 